\title{
CORRESPONDENCE
}

Kidney Donor Cards

Sir Michael Woodruff, F.R.C.S., F.R.S. . . . 346

Patients Who Can Kill

D. C. Watt, F.R.C.PSYCH.............346

Hepatitis B Antigen in V.D. Clinic Patients

J. Wallace, F.R.C.P.GLASG., F.R.C.PATH. . . . . 347

Confidentiality

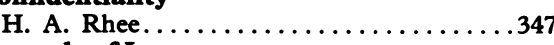

Hazards of Laparoscopy

P. C. Steptoe, F.R.C.o.G. . . . . . . . . . . . 347

Toxicity of Benorylate

M. Aylward, м.в...................

Fenfluramine and Growth Hormone

Release

Elizabeth M. E. Poskitt, M.R.C.P., and P. H

W. Rayner, M.R.C.P.; M. H. Lessof, F.R.C.P.,

and S. McHardy-Young, M.R.C.P.........349

Is Your Pain Really Necessary?

V. R. Pickles, M.D...................... 349

Side Efiects of the Pill

Ellen C. G. Grant, M.B. . . . . . . . . . . . . . 349

"Easy to Rise" Chair

A. N. G. Clark, M.D. . . . . . . . . . . . 349

Riot Control Agent

J. D. Whittall, L.M.S.S.A. . . . . . . . . . . . . 350

Haemolytic-Uraemic Syndrome with

Pericarditis

J. Guardia, M.D., and others..........350

Renal Carbuncle

G. T. Watts, F.R.c.s. . . . . . . . . 350
Antibiotic Sensitivity of Klebsiella

T. D. M. Martin, F.R.C.PATH. . . . . . . 350

Administration of Bronchodilators to Young Children

S. C. Shore, M.R.C.P., and E. G. Weinberg,

F.C.P.(s.A.) $\ldots \ldots \ldots \ldots \ldots \ldots \ldots \ldots \ldots \ldots$

Potassium Deficiency during Treatment with Brinaldix $K$

E. R. Evans, M.D...... . . . . . . . . . . 350

Transient Synovitis and Perthes's Disease

C. P. Monty, F.R.C.S. . . . . . . . . . 350

Coalworkers' Pneumoconiosis

H. Campbell, M.B., F.F.C.M., and others. . . . 351

Misuse of Drugs Regulations 1973

V. E. Coleman, M.B................ 351

The Community Hospital

I. V. Lishman, F.R.C.s. . . . . . . . . 351

Hospital Activity Analysis Statistics

P. D. Rohde, M.R.C.P., M.R.C.PSYCH. . . . . . 351

Ampicillin for Sore Throat

A. A. Robertson, M.R.C.G.P... .

Active Management of Labour

R. J. Lennane, M.R.A.C.P., and K. Jean Lennane,

M.R.C.A.P.; D. W. Ryan, M.B........... 352

Infantile Herpes Zoster

G. D. W. McKendrick, F.R.C.P., and S. C.

Raychoudhury, M.R.C.P............. 352

Treatment of Hypothyroidism

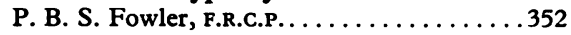

Pancytopenia after Administration of Distalgesic

Gillian K. Webster, M.B. ............353

Thalassaemia in the British

J. J. Taylor, M.R.C.PATH. . . . . . . . . . 353

Hazards of Central Venous Catheterization

M. J. McMahon, F.R.C.S............353

New Eye Hazard

F. R. Neubert, M.D., D.o.M.S. . . . . . . . . 353

Sex and Social Class

J. P. Lester, M.R.C.G.P. . . . . . . . . . . 354

Nasal Polyps

R. W. Smithells, F.R.C.P.; J. C. Delaney,

M.R.C.P...................... 354

Penicillin in Leptospirosis

L. J. Clein, M.D ... . . . . . . . . . . . 354

Prevalence of Varicose Veins in Africans

W. G. Daynes, M.R.C.s., and P. H. Beighton,

M.D. . . . . . . .............. 354

Classification of Skin Diseases

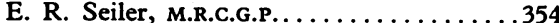

Prescription Charges in Chronic Illness

Elizabeth Segall.................. 354

Consultants' Superannuation

J. Winter, M.D.................... 355

General Practitioners' Superannuation

N. F. Field, M.B. . . . . . . . . . . . . . 355

Earnings of G.P.s and Hospital Doctors

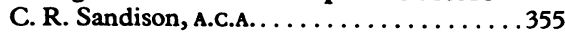

SIR,-May I make one or two comments on your short but helpful leading article (28 July, p. 189).

As you point out, the period immediately following a sudden and unexpected death, often of a young subject, is an inappropriate time at which to have to seek permission about removing kidneys for transplantation. In my experience many relatives, when they consider this matter a little later on, feel that something significant has been salvaged from the wreck if the deceased person's kidneys have been used to save the lives of others. They require time, however, to recover from the impact of what has happened before they find it easy to make a decision about whether or not to allow organs to be removed for transplantation, or indeed on any other matter.

It seems to me important therefore that if the deceased has signed, and was carrying at the time of his death, a kidney transplant donor card there should be no necessity for doctors wishing to remove kidneys to approach the relatives at all at this time. You appear to assume that this is in fact the case, but some of the lawyers with whom I have discussed the matter have expressed the view that as the law now stands a doctor would be wise to consult the relatives in every case, irrespective of whether the deceased was carrying a donor cand or not. If this view is correct, a good deal of the supposed benefit of card carrying has been lost. It would seem desirable therefore to seek counsel's opinion on this matter, and if there is doubt about the propriety of not approaching the relatives when the deceased person is carrying a donor card, then amending legislation should be sought to put this matter right.-I am, etc.,

Department of Surgery,

MICHAEL WOODRUFF Eniversity

**An article by our legal ccrrespondent reviewing the law concerning the removal of organs from human bodies ippears in this issue at p. 360 -ED., B.M.J.

\section{Patients Who Can Kill}

SIR,-The thoughtful article by your legal correspondent (28 July, p. 241) concerning the tragic killing of a baby by a former patient of this hospital will perhaps gain value by the addition of some facts not apparent from the accounts of the trial.

Mrs. Parslow had been an informal patient on each of her admissions to this hospital, the first in early 1972. The diagnosis was an obsessional neurosis in an unstable personality, the latter exacerbated by difficult social circumstances. She was never diagnosed as a schizophrenic. She discharged herself from hospital and between admissions was seen as an outpatient. Although she had taken an overdose of tablets on three occasions, she did not at any time show or threaten physical aggression and gave no reason to suppose that she would.

To the small part of my observations to the press which you have quoted should be added that, given the same situation and knowledge that I believe Dr. Burch had, I would not have recommended Mrs. Parslow's detention.

Contrary to what is stated in the account of the Court proceedings, Mrs. Parslow was not pregnant in this hospital and she was an outpatient for the consideration of terminating her pregnancy. Though the judge was horrified that her pregnancy was not terminated despite the fact that "she was quite unfit to be a mother" it should be noted that unfitness (in the sense of unsuitability) to be a mother is not a legal ground for abortion. The doctor whom she saw made a very full and careful inquiry and I can say that, while acknowledging the decision to be a matter of judgement, I believe his to have been the only one he could have come to. She, in fact, refused to have an abortion at that time.

Your correspondent rightly points out "the awful consequences that may follow if a patient's true mental state [that is, intent to murder] is not recognized in advance". I do not believe that this could reasonably have been prognosticated from what the doctors knew of Mrs. Parslow before she killed a child.-I am, etc.

David C. WatT, Medical Director,
St. John's Hospital

Stone

Aylesbury, Bucks 